\title{
Cefepime shows good efficacy and no antibiotic resistance in pneumonia caused by Serratia marcescens and Proteus mirabilis - an observational study
}

Josef Yayan $^{1 *} \mathbb{D}$, Beniam Ghebremedhin ${ }^{2}$ and Kurt Rasche ${ }^{1}$

\begin{abstract}
Background: Many antibiotics have no effect on Gram-positive and Gram-negative microbes, which necessitates the prescription of broad-spectrum antimicrobial agents that can lead to increased risk of antibiotic resistance. These pathogens constitute a further threat because they are also resistant to numerous beta-lactam antibiotics, as well as other antibiotic groups. This study retrospectively investigates antimicrobial resistance in hospitalized patients suffering from pneumonia triggered by Gram-negative Serratia marcescens or Proteus mirabilis.

Methods: The demographic and clinical data analyzed in this study were obtained from the clinical databank of the HELIOS Clinic, Witten/Herdecke University, Wuppertal, Germany, for inpatients presenting with pneumonia triggered by S. marcescens or P. mirabilis from 2004 to 2014. An antibiogram was conducted for the antibiotics utilized as part of the management of patients with pneumonia triggered by these two pathogens.

Results: Pneumonia was caused by Gram-negative bacteria in 115 patients during the study period from January 1 , 2004, to August 12, 2014. Of these, 43 (37.4\%) hospitalized patients [26 males (60.5\%, $95 \% \mathrm{Cl} 45.9 \%-75.1 \%)$ and 17 females (39.5\%, $95 \%$ Cl $24.9 \%-54.1 \%)]$ with mean age of $66.2 \pm 13.4$ years had pneumonia triggered by S. marcescens, while 20 (17.4\%) patients [14 males (70\%, $95 \%$ Cl $49.9 \%-90.1 \%)$ and 6 females (30\%, $95 \%$ Cl $9.9 \%-50.1 \%)$ ] with a mean age of $64.6 \pm 12.8$ years had pneumonia caused by P. mirabilis. S. marcescens showed an increased antibiotic resistance to ampicillin (100\%), ampicillin-sulbactam (100\%), and cefuroxime (100\%). P. mirabilis had a high resistance to tetracycline $(100 \%)$ and ampicillin $(55 \%)$. S. marcescens $(P<0.0001)$ and $P$. mirabilis $(P=0.0003)$ demonstrated no resistance to cefepime in these patients with pneumonia.
\end{abstract}

Conclusions: S. marcescens and P. mirabilis were resistant to several commonly used antimicrobial agents, but showed no resistance to cefepime.

Keywords: Serratia marcescens, Proteus mirabilis, Cefepime, Pneumonia, Antibiotic, Sensitivity, Resistance

\footnotetext{
* Correspondence: josef.yayan@hotmail.com

${ }^{1}$ Department of Internal Medicine, Division of Pulmonary, Allergy and Sleep

Medicine, HELIOS Clinic Wuppertal, Witten/Herdecke University, Witten,

Germany

Full list of author information is available at the end of the article
} 


\section{Background}

Serratia marcescens and Proteus mirabilis are Gramnegative bacteria that can cause pneumonia-an acute infection of the lower airways caused by airborne infection or by infection transferred from another part of the body via the bloodstream [1]. Gram-negative bacteria are less often the cause of community- and nosocomialacquired pneumonia when compared to Gram-positive bacteria [2-4].

S. marcescens is the most common species of the Enterobacteriaceae family responsible for nosocomial infections [5, 6]. Proteus species are other Gram-negative bacteria from the Enterobacteriaceae family [7], with $P$. mirabilis being a medically prominent species [8]. Proteus spp. cause most of the common urinary tract infections and are less frequently the causes of infections in other locations, including pneumonia [8].

Penicillin has reliably helped to treat potentially fatal bacterial infections for many decades [9]. However, antibiotics have lost their effectiveness due to the increasing antibiotic resistance expressed by microbes [10]. Many antibiotic resistant Gram-positive pathogens are recognized, but antibiotic resistance is also becoming increasingly common in Gram-negative bacteria [11]. Grampositive and Gram-negative microorganisms often can only be fought with different antibiotics, making the timely use of effective antibiotics particularly important in patients with pneumonia.

Early identification of specific resistance characteristics can result in a more effective use of antibiotics and can limit the use of broad-spectrum antibiotics to serious infections, thereby helping to prevent the development of antibiotic resistance in $S$. marcescens and $P$. mirabilis. Early isolation of infected patients can also help to stop the spread of resistant bacteria.

For these reasons, this research was performed to identify the antibiotics to which $S$. marcescens and $P$. mirabilis have shown resistance over the past 10 years. The records of the HELIOS Clinic at Witten/Herdecke University in Wuppertal, Germany were searched to gather all relevant files on hospitalized patients suffering from pneumonia triggered by $S$. marcescens and $P$. mirabilis and classified according to the International Classification of Diseases (ICD) code J15.6 [12, 13]. The goal of this investigation was to determine the most effective selection of active antibiotics against S. marcescens and $P$. mirabilis, in order to reduce the suffering of patients, shorten the duration of hospital stays, and decrease the number of deaths.

\section{Methods}

\section{Patients}

This retrospective observational study analyzed antibiotic resistance in all hospitalized patients over the age of 18 years with identified pneumonia triggered by $S$. marcescens or $P$. mirabilis. A parallel evaluation was made of the antibiotic sensitivity and resistance of patients with pneumonia caused by $S$. marcescens and with pneumonia due to $P$. mirabilis. All appropriate data were acquired from files in the hospital databank of the HELIOS Clinic at Witten/Herdecke University in Wuppertal, Germany, for the duration of this investigation from January 1, 2004, to August 12, 2014.

\section{Definition of pneumonia}

Pneumonia is an acute inflammation of the lower airways that can be triggered by $S$. marcescens or $P$. mirabilis. The characteristic clinical signs of pneumonia are productive cough, chest pain, fever, and shortness of breath. Pneumonia is identified by chest X-ray investigation and expectorant cultures [12, 13].

Community-acquired pneumonia triggered by $S$. marcescens or $P$. mirabilis is an acute respiratory tract infection picked up from ordinary communal interaction with the public; this differs from nosocomial-acquired pneumonia triggered by $S$. marcescens or $P$. mirabilis, which occurs during hospitalization [14].

After a first empirical antibacterial treatment, the diagnosis of pneumonia caused by $S$. marcescens or $P$. mirabilis was based on the specific criteria that all patients were hospitalized, all presented new areas of infiltration on X-ray investigation, and all had novel clinical symptoms, including a minimum of two of the following symptoms: difficulty breathing, fever over $38{ }^{\circ} \mathrm{C}$, sputum production, and coughing.

\section{Investigated antibiotics}

The effectiveness of the following antibiotics was examined against $S$. marcescens and P. mirabilis by susceptibility testing: ampicillin, piperacillin, ampicillin-sulbactam, cefotaxime, cefuroxime, piperacillin-tazobactam, ceftazidime, cefepime, meropenem, tobramycin, imipenem, levofloxacin, ciprofloxacin, gentamicin, co-trimoxazole, tetracycline, tigecycline, amikacin, and fosfomycin.

The incidence was noted of the application of the above antimicrobial agents in clinical use for the therapy of inpatients suffering from pneumonia triggered by $S$. marcescens or $P$. mirabilis. The rate of susceptibility testing of these antibiotics after discovery of S. marcescens or $P$. mirabilis was also recorded. $S$. marcescens and $P$. mirabilis causing pneumonia were assessed for susceptibility to antibiotics and then the antimicrobial agent showing the greatest resistance was checked against the other antibiotics.

For Gram-negative pathogens, minimal inhibitory concentration (MIC) breakpoints were utilized that corresponded to the antibiotic susceptibility testing guidelines established by the Clinical and Laboratory Standards 
Institute (CLSI) for 2004 - 2011 [15], and by the European Committee on Antimicrobial Susceptibility Testing (EUCAST) for 2012 - 2014 [16].

\section{Detection and antimicrobial susceptibility testing} Gram-negative bacteria were identified based on growth on chocolate agar that included bacitracin $\left(\mathrm{BD}^{\mathrm{m} x}\right.$ MacConkey Agar, Becton Dickinson, Heidelberg) after incubation for $18-48 \mathrm{~h}$ at $37{ }^{\circ} \mathrm{C}$ with $5 \% \mathrm{CO}_{2}$. These bacteria were identified as oxidase-positive, porphyrinnegative bacteria needing nicotinamide adenine dinucleotide plus heme in addition to missing betahemolysis on horse blood agar plates, and by MALDITOF-MS (Matrix Assisted Laser Desorption Ionization Time-of-Flight-Mass Spectrometry, Bruker, Bremen, Germany). Software suitable for the interpretation of susceptibility testing results using the EUCAST breakpoints for 2012 - 2014 was utilized for the antimicrobial susceptibility testing [16]. Gram-negative isolates were additionally examined using the API NH biochemical reaction technique for the detection of Neisseria and Haemophilus species (bioMérieux, Marcy-l'Étoile, France) and by MALDI-TOF MS analysis (Daltonik, Bremen, Germany).

\section{EUCAST standardized disc diffusion method}

The disc diffusion method established by Kirby-Bauer was carried out for antimicrobial susceptibility testing [17]. Mueller-Hinton culture medium was supplemented with $5 \%$ horse blood and $20 \mathrm{mg} / \mathrm{L}$ beta-nicotinamide adenine dinucleotide (BD, Heidelberg, Germany). Plates were inoculated with samples of each isolate and set to a turbidity of 0.5 McFarland. Antibiotic discs were applied to the dried surface of the inoculated culture medium and later incubated at $35 \pm 1{ }^{\circ} \mathrm{C}$ for $18 \pm 2 \mathrm{~h}$ in a $5 \%$ $\mathrm{CO}_{2}$ atmosphere. In cases of discrepancies or insufficient readings, the accurate determination of the MIC was executed by an E-test for particular pathogens, and the outcomes were interpreted according to the EUCAST criteria [16]. Intermediate isolates were grouped together with resistant isolates. Beta-lactamase production was evaluated using the nitrocefin test (Oxoid, Wesel, Germany). Gram-negative strains were described as beta-lactamase-negative strains that were resistant to ampicillin (zone diameter $>16 \mathrm{~mm}$ or $\mathrm{MIC} \geq 4 \mu \mathrm{g} / \mathrm{mL}$ ) [16]. Inhibition zone diameters were based on the 2014 EUCAST guidelines [16].

\section{Microbiology}

Bronchoalveolar lavage using fiber-optic video bronchoscopy was performed for microbiological examination of secretions from the pulmonary airways. After administration of local anesthesia, approximately $20 \mathrm{ml}$ of isotonic saline was administered and aspirated by means of the fiber-optic bronchoscope into three special sterilized 40-ml sample containers. In this way, tracheal secretions were also obtained by means of bronchoscopy. Throat smears were obtained by turning a sterile cotton swab (MEUS Srl, Piove di Sacco, Italy) along the throats of inpatients presumed to have pneumonia. Expectorate was collected by ejection into $30-\mathrm{ml}$ antiseptic sputumcollection containers (Salivette, SARSTEDT, Nümbrecht, Germany). The ejections, as well as the tracheal and bronchial secretions, were Gram stained and examined by light microscopy at $80-1,000$-fold magnification in a minimum of five viewing fields, following the principles of Bartlett [18]. Three basic culture media were then prepared for the growth of commonly occurring, rapidly growing aerobic microbes.

\section{Blood cultures}

A least $20 \mathrm{ml}$ of blood were added to two special culture media, BACTEC Plus Aerobic/F and Plus Anaerobic/F medium (BD, Becton, Dickinson and Company, Heidelberg, Germany).

\section{Duration of hospital stay}

The lengths of hospital stays were compared between patients with pneumonia caused by $S$. marcescens or $P$. mirabilis.

\section{Mortality}

The number of fatalities during hospital stays was measured in the study population. The survival rates were calculated by the Kaplan-Meier method.

\section{Statistical analysis}

The nominal variables were stated in percentages and continuous data were indicated as mean \pm standard deviation (SD). Two-tailed tests were calculated. The results were executed at a $95 \%$ confidence interval (CI) for the sex differentiation of inpatients suffering from pneumonia triggered by $S$. marcescens or $P$. mirabilis. A chisquare test for two free variables of three possibilities was calculated on the VassarStats website for statistical calculation to determine whether $S$. marcescens and $P$. mirabilis were sensitive, intermediate, or resistant to antimicrobial agents, and to calculate acquisitions of pneumonia. A chi-square test was performed for two free variables of two possibilities for gender differences and deaths, and another chi-square test was performed for two free variables of five possibilities for specimens [19]. One-way analysis of variance (ANOVA) for two independent samples was performed to compare age differences, duration of hospital stay, and laboratory tests of patients with pneumonia caused by $S$. marcescens or $P$. mirabilis. Statistical significance was defined as a $P$ value of less than 0.05 . 


\section{Ethics statement}

The procedures of this retrospective study were performed in agreement with the established official guidelines of Witten/Herdecke University. All patient data were anonymized before evaluation. The Ethics Committee of Witten/Herdecke University approved this study protocol. Due to the retrospective nature of the study protocol, the committee waived the need for written informed consent.

\section{Results}

A total of 6,932 patients of all ages were found with pneumonia triggered by diverse kinds of microorganisms at the HELIOS Clinic at Witten/Herdecke University in Wuppertal, Germany at the time of this clinical study from January 1, 2004, to August 12, 2014. Of these, 115 (1.7 \%, 95 \% CI 1.4 \%-2.0 \%) inpatients had pneumonia triggered by Gram-negative bacteria (ICD J15.6). A total of 43 (37.4 \%, $95 \%$ CI $28.6 \%-46.2 \%)$ inpatients were identified for this investigation as having pneumonia triggered by S. marcescens, and 20 (17.4 \%, $95 \% \mathrm{CI}$ $10.5 \%-24.3 \%$ ) inpatients had pneumonia due to $P$. mirabilis. Males were more frequently diagnosed with pneumonia triggered by $S$. marcescens or $P$. mirabilis (Table 1). No gender difference was found when comparing patients with pneumonia caused by $S$. marcescens or P. mirabilis (Table 1). S. marcescens and P. mirabilis infections were responsible for the most nosocomialacquired pneumonia (Table 1). Gram-negative bacteria were discovered in most tracheal secretions in both groups of patients infected by these two organisms (Table 1). The duration of hospital stays did not differ between the two groups (Table 1).

An increase in cases of pneumonia was found over the years of the study period (Fig. 1). The peak number of cases of pneumonia due to $S$. marcescens occurred in 2010 and due to P. mirabilis in 2011 (Fig. 1).

Two kinds of Gram-negative bacteria were discovered in the same patient in 9 cases with pneumonia. The other Gram-negative bacteria, apart from $S$. marcescens (43) and P. mirabilis (20), causing pneumonia during this study period were Escherichia coli (10 cases), Enterobacter cloacae (7), Stenotrophomonas maltophilia (6), Acinetobacter baumannii (5), Enterobacter aerogenes (3), Citrobacter koseri (1), Moraxella catarrhalis (1), Prevotella buccae (1), Proteus vulgaris (1), Citrobacter koseri (1), and Serratia plymuthica (1).

Fifty-two inpatients were excluded from this investigation due to infectious diseases triggered by other Gramnegative bacteria (37) or found in other locations in the body (15), or because of a lack of access to their records on the wards of the neurological department. In addition, all children and adolescents under the age of 18 with pneumonia triggered by $S$. marcescens or P. mirabilis, and who were hospitalized on the wards of the Division of Child and Adolescent Health, were excluded.

The number of examinations for each antimicrobial agent differed in this investigation because a few isolates

Table 1 Demographic data, acquisition of pneumonia, length of hospital stay, mortality rate, and different discovery methods of Serratia marcescens and Proteus mirabilis infection in patients with pneumonia

\begin{tabular}{|c|c|c|c|}
\hline Total No. of Gram-negative bacteria pneumonia $=115$ & Serratia marcescens (\%) & Proteus mirabilis (\%) & $P$ value \\
\hline No. of patients & $43(37.4)$ & $20(17.4)$ & \\
\hline \multicolumn{4}{|l|}{ Gender } \\
\hline Male & $26(60.5)$ & $14(70)$ & 0.655 \\
\hline Female & $17(39.5)$ & $6(30)$ & 0.655 \\
\hline Age mean + SD (years) & $66.2 \pm 13.4$ & $64.6 \pm 12.8$ & 0.648 \\
\hline \multicolumn{4}{|l|}{ Acquisition of pneumonia } \\
\hline Community-acquired pneumonia & $15(34.9)$ & $6(30)$ & 0.083 \\
\hline Nosocomial-acquired pneumonia & $23(53.5)$ & $7(35)$ & 0.083 \\
\hline Aspiration pneumonia & $5(11.6)$ & $7(35)$ & 0.083 \\
\hline \multicolumn{4}{|l|}{ Specimens } \\
\hline Tracheal secretions & $33(76.7)$ & $9(45)$ & 0.056 \\
\hline Bronchial secretions & $7(16.3)$ & $5(25)$ & 0.056 \\
\hline Sputum & $1(2.3)$ & $2(10)$ & 0.056 \\
\hline Throat swab & 0 & $2(10)$ & 0.056 \\
\hline Venous blood culture & $2(4.7)$ & $2(10)$ & 0.056 \\
\hline Duration of hospital stay mean \pm SD (days) & $22.2 \pm 18.1$ & $18.4 \pm 13.4$ & 0.392 \\
\hline No. of deaths & $7(16.3)$ & $3(15)$ & 0.807 \\
\hline
\end{tabular}

Abbreviations: SD standard deviation 


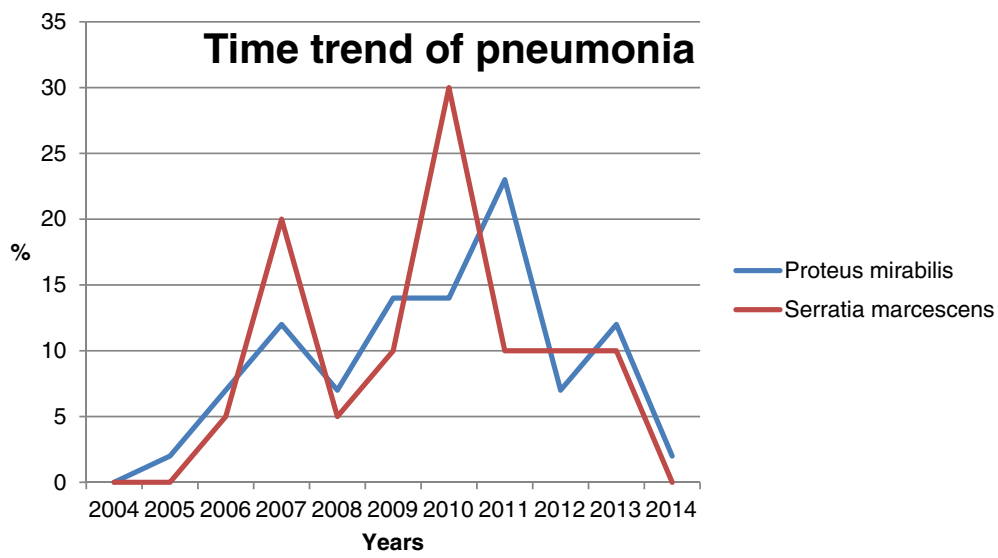

Fig. 1 Time trend of pneumonia due to Serratia marcescens and Proteus mirabilis from 2004 to 2014

Table 2 Antibiotic sensitivity and antibiotic resistance for different drug groups in patients with pneumonia caused by Serratia marcescens

\begin{tabular}{|c|c|c|c|c|c|c|c|}
\hline \multicolumn{8}{|l|}{$\begin{array}{l}\text { No. of patients with } \\
\text { S. marcescens }=43\end{array}$} \\
\hline Drug groups & $\begin{array}{l}\text { Active } \\
\text { substance }\end{array}$ & $\begin{array}{l}\text { No. using } \\
\text { antibiotics (\%) }\end{array}$ & $\begin{array}{l}\text { No. of tests of } \\
\text { antibiotics on } \\
\text { antibiogram (\%) }\end{array}$ & Sensitive (\%) & Intermediate (\%) & Resistant (\%) & $\begin{array}{l}P \text { value } \\
\text { compared } \\
\text { to ampicillin }\end{array}$ \\
\hline \multirow[t]{2}{*}{ Penicillins } & Ampicillin & 0 & $43(100)$ & 0 & 0 & $43(100)$ & \\
\hline & Piperacillin & 0 & $43(100)$ & $31(72.1)$ & $5(11.6)$ & $7(16.3)$ & $<0.0001$ \\
\hline \multirow{2}{*}{$\begin{array}{l}\text { Penicillin + } \\
\text { Beta-lactamase } \\
\text { inhibitors }\end{array}$} & $\begin{array}{l}\text { Ampicillin + } \\
\text { Sulbactam }\end{array}$ & $3(7.0)$ & $43(100)$ & 0 & 0 & $43(100)$ & 1.0 \\
\hline & $\begin{array}{l}\text { Piperacillin + } \\
\text { Tazobactam }\end{array}$ & $21(48.8)$ & $43(100)$ & 38 (88.3) & $1(2.3)$ & $4(9.3)$ & $<0.0001$ \\
\hline \multirow[t]{4}{*}{ Cephalosporins } & Cefepime & $2(4.7)$ & $39(90.7)$ & $39(100)$ & 0 & 0 & $<0.0001$ \\
\hline & Cefotaxime & 0 & $43(100)$ & $36(83.7)$ & $2(4.7)$ & $5(11.6)$ & $<0.0001$ \\
\hline & Ceftazidime & $1(2.3)$ & 39 (90.7) & $39(100)$ & 0 & 0 & $<0.0001$ \\
\hline & Cefuroxime & $4(9.3)$ & $43(100)$ & 0 & 0 & $43(100)$ & 1.0 \\
\hline \multirow[t]{2}{*}{ Glycylcycline } & Tetracycline & 0 & $17(39.5)$ & $3(17.6)$ & $2(11.8)$ & $12(70.6)$ & 0.001 \\
\hline & Tigecycline & 0 & $5(11.6)$ & $3(60.0)$ & $2(40.0)$ & 0 & $<0.0001$ \\
\hline \multirow[t]{2}{*}{ Carbapenems } & Imipenem & $5(11.6)$ & $43(100)$ & $42(97.7)$ & 0 & $1(2.3)$ & $<0.0001$ \\
\hline & Meropenem & $2(4.7)$ & $42(97.7)$ & $41(97.6)$ & $1(2.4)$ & 0 & $<0.0001$ \\
\hline \multirow[t]{2}{*}{ Gyrase inhibitors } & Ciprofloxacin & $4(9.3)$ & $42(97.7)$ & 37 (88.1) & $2(4.8)$ & $3(7.1)$ & $<0.0001$ \\
\hline & Levofloxacin & $3(7.0)$ & $28(65.1)$ & 26 (92.9) & 0 & $2(7.1)$ & $<0.0001$ \\
\hline \multirow[t]{3}{*}{ Aminoglycoside } & Amikacin & 0 & $26(60.5)$ & $18(69.2)$ & $8(30.8)$ & 0 & $<0.0001$ \\
\hline & Gentamicin & $2(4.7)$ & $40(93.0)$ & $38(95.0)$ & $2(5.0)$ & 0 & $<0.0001$ \\
\hline & Tobramycin & 0 & $27(62.8)$ & 16 (59.3) & $4(14.8)$ & $7(25.9)$ & $<0.0001$ \\
\hline $\begin{array}{l}\text { Trimethoprim + } \\
\text { Sulfamethoxazole }\end{array}$ & $\begin{array}{l}\text { Co- } \\
\text { trimoxazole }\end{array}$ & 0 & $42(97.7)$ & 39 (92.9) & 0 & $3(7.1)$ & $<0.0001$ \\
\hline Others & Fosfomycin & 0 & $17(39.5)$ & $17(100)$ & 0 & 0 & $<0.0001$ \\
\hline
\end{tabular}

Note: Significant $P$ values shown in bold 
were tested according to the CLSI guidelines, while others were tested corresponding to the EUCAST guidelines over the past few years. In general, the sums of the susceptibility tests were greater for the antibiograms obtained according to the CLSI guidelines (Tables 2 and 3).

The most-used antibiotic in patients with pneumonia due to $S$. marcescens or P. mirabilis in this research was piperacillin-tazobactam (Tables 2 and 3).

Among the inpatients with pneumonia triggered by $S$. marcescens or P. mirabilis, no resistance was found to cefepime when compared to ampicillin; this finding was statistically significant (Tables 2 and 3). S. marcescens and $P$. mirabilis had the highest antibiotic-resistance rates toward ampicillin, compared to cefepime, in this research (Tables 2 and 3). S. marcescens also had an elevated antibiotic-resistance rate toward ampicillin, as correlated with the ampicillin-sulbactam combination used in this study (Table 2).

The mortality rate did not statistically differ between the study groups. The survival rate was $83.7 \%$ (95 \% CI $71.7 \%-95.8 \%)$ in the study population with pneumonia triggered by $S$. marcescens and $85.0 \%$ (95 \% CI $68.0 \%-102.0 \%$ ) in in the group infected with $P$. mirabilis (Table 1).

\section{Discussion}

In general, $S$. marcescens and $P$. mirabilis are bacterial strains that are not frequently found in pneumonia patients, as was also the case in the present study. No antibiotic resistance developed to cefepime-an antimicrobial agent administered to patients with pneumonia - in either $S$. marcescens or P. mirabilis during this ten-year, qualitative, controlled observational investigation. An earlier clinical study comparing the effectiveness of cefepime to six other antibiotics commonly used in the management of severe infections triggered by Gram-negative pathogens indicated that the most effective antibiotics were cefepime and imipenem [20]. A comparable result was found in another investigation that evaluated cefepime as an initial antibiotic treatment for Gram-negative pneumonia. A previous study had compared beta-lactam antibiotics against

Table 3 Antibiotic sensitivity and antibiotic resistance in different drug groups in patients with pneumonia caused by Proteus mirabilis

\begin{tabular}{|c|c|c|c|c|c|c|c|}
\hline \multicolumn{8}{|l|}{$\begin{array}{l}\text { No. of patients } \\
\text { with P. mirabilis }=20\end{array}$} \\
\hline Drug groups & $\begin{array}{l}\text { Active } \\
\text { substance }\end{array}$ & $\begin{array}{l}\text { No. using } \\
\text { antibiotics (\%) }\end{array}$ & $\begin{array}{l}\text { No. of tests of } \\
\text { antibiotics on } \\
\text { antibiogram (\%) }\end{array}$ & Sensitive (\%) & Intermediate (\%) & Resistant (\%) & $\begin{array}{l}P \text { value } \\
\text { compared to } \\
\text { ampicillin }\end{array}$ \\
\hline \multirow[t]{2}{*}{ Penicillins } & Ampicillin & 0 & $20(100)$ & $8(40.0)$ & $1(5.0)$ & $11(55.0)$ & \\
\hline & Piperacillin & $1(5.0)$ & $20(100)$ & $13(65.0)$ & $4(20.0)$ & $3(15.0)$ & 0.023 \\
\hline \multirow[t]{2}{*}{$\begin{array}{l}\text { Penicillin + Beta- } \\
\text { lactamase inhibitors }\end{array}$} & $\begin{array}{l}\text { Ampicillin + } \\
\text { Sulbactam }\end{array}$ & $3(15.0)$ & $20(100)$ & $13(65.0)$ & $3(15.0)$ & $4(20.0)$ & 0.065 \\
\hline & $\begin{array}{l}\text { Piperacillin + } \\
\text { Tazobactam }\end{array}$ & $15(75.0)$ & $20(100)$ & $20(100)$ & 0 & 0 & 0.0002 \\
\hline \multirow[t]{4}{*}{ Cephalosporins } & Cefepime & 0 & $19(95.0)$ & $19(100)$ & 0 & 0 & 0.0003 \\
\hline & Cefotaxime & 0 & $20(100)$ & $18(90.0)$ & 0 & $2(10.0)$ & 0.004 \\
\hline & Ceftazidime & $1(5.0)$ & $16(80.0)$ & $16(100)$ & 0 & 0 & 0.0007 \\
\hline & Cefuroxime & 0 & $20(100)$ & $15(75.0)$ & 0 & $5(25.0)$ & 0.068 \\
\hline \multirow[t]{2}{*}{ Glycylcycline } & Tetracycline & 0 & $13(65.0)$ & 0 & 0 & $13(100)$ & 0.018 \\
\hline & Tigecycline & 0 & $1(5.0)$ & $1(100)$ & 0 & 0 & 0.497 \\
\hline \multirow[t]{2}{*}{ Carbapenems } & Imipenem & $3(15.0)$ & $20(100)$ & $19(95.0)$ & $1(5.0)$ & 0 & 0.0004 \\
\hline & Meropenem & 0 & $19(95.0)$ & $18(94.7)$ & $1(5.3)$ & 0 & 0.0006 \\
\hline \multirow[t]{2}{*}{ Gyrase inhibitors } & Ciprofloxacin & $1(5.0)$ & $18(90.0)$ & $15(83.3)$ & $1(5.6)$ & $2(13.3)$ & 0.016 \\
\hline & Levofloxacin & $1(5.0)$ & $14(70.0)$ & $13(92.9)$ & $1(7.1)$ & 0 & 0.003 \\
\hline \multirow[t]{3}{*}{ Aminoglycoside } & Amikacin & 0 & $9(45.0)$ & $9(100)$ & 0 & 0 & 0.01 \\
\hline & Gentamicin & $2(10.0)$ & $19(95.0)$ & $16(84.2)$ & 0 & $3(15.8)$ & 0.080 \\
\hline & Tobramycin & 0 & $11(55.0)$ & $8(72.7)$ & $1(9.1)$ & $2(18.2)$ & 0.139 \\
\hline $\begin{array}{l}\text { Trimethoprim + } \\
\text { Sulfamethoxazole }\end{array}$ & $\begin{array}{l}\text { Co- } \\
\text { trimoxazole }\end{array}$ & 0 & $20(100)$ & $14(70.0)$ & 0 & $6(30.0)$ & 0.321 \\
\hline Others & Fosfomycin & 0 & $5(25.0)$ & $5(100)$ & 0 & 0 & 0.056 \\
\hline
\end{tabular}


all Gram-negative pathogens that cause pneumonia, and based on that study's outcome, cefepime was suggested as an initial therapy for nosocomial-acquired pneumonia triggered by Gram-negative pathogens [21].

Similar resistance rates were found for amikacin and fosfomycin in the present work. Note, however, that the sensitivities of these two antibiotics were significantly lower than that of cefepime in this investigation. Amikacin has known effectiveness against Gram-negative bacteria [22].

A previous retrospective study that investigated the optimal first-antibiotic regimen for nosocomial-acquired pneumonia triggered by Gram-negative bacteria detected in sputum [23] indicated good effectiveness with imipenem $(75 \%)$ and amikacin (84 \%), based on antibiogram results. In comparison, the sensitivity rate determined in the present study was higher for imipenem $(97.7 \%)$ and considerably lower for amikacin (69.2\%). The earlier study took Pseudomonas into account in the evaluation of the Gram-negative bacteria, but a direct comparison of studies is often complicated because different conspecifics were investigated under the collective term "Gram-negative bacteria" [23].

The clinical efficacy of cefepime was previously confirmed by comparative and non-comparative studies conducted many years ago $[23,24]$. Cefepime was considered useful in the management of pneumonia, and it is also active against organisms that show resistance to other drugs [23, 24]. Fosfomycin is widely used for nosocomial-acquired infections in hospitals because of its good efficacy against Gram-negative bacteria $[25,26]$. It can also be used in infections of the airways [27]. Meropenem is a broad-range antimicrobial agent effective against Gram-positive and Gram-negative germs [28] and has shown excellent efficacy in clinical studies for the management of severe pneumonia in critical patients [29]. Meropenem also showed good effectiveness and relatively low resistance in all inpatients with pneumonia due to $S$. marcescens and $P$. mirabilis over the course of the present clinical research.

Good results were also found for levofloxacin in a previous study [29]. Levofloxacin was likewise found to be effective in the present study for the management of patients with pneumonia triggered by $S$. marcescens or $P$. mirabilis. The development of resistance to levofloxacin was relatively low over the 10 -year period covered by the present investigation. It has good bacteriological effectiveness against a variety of infection diseases, and it is also approved for the antibiotic management of nosocomial-acquired infections [30].

When compared to levofloxacin, imipenem showed better efficacy and a somewhat poorer resistance rate in the present clinical study of hospitalized patients with pneumonia triggered by $S$. marcescens or $P$. mirabilis.
Another study arrived at the same conclusion, where levofloxacin was as effective as imipenem and was tolerated well in patients with nosocomial-acquired pneumonia [31].

A nationwide study conducted in Japan concluded that ciprofloxacin had favorable susceptibility rates for treatment of Gram-negative bacterial pneumonia [32], in agreement with the findings of the present study. Another study that examined the effect of intravenous administration of ciprofloxacin on nosocomial-acquired pneumonia proposed intravenous ciprofloxacin as the first choice for nosocomial-acquired pneumonia triggered by both Gram-positive and Gram-negative microbes [33].

Gentamicin is mostly effective against Gram-negative microorganisms and shows activity against staphylococci [34]. It had relatively good activity in the present study in patients with pneumonia triggered by $S$. marcescens or $P$. mirabilis. Both $S$. marcescens and $P$. mirabilis showed resistance to gentamicin.

Ceftazidime is a valuable alternative for the management of nosocomial-acquired pneumonia; nevertheless, its role as an effective antimicrobial agent has decreased over the past decade due to the strong increase in resistance rates, especially for Pseudomonas aeruginosa and Acinetobacter baumannii [35]. Pseudomonas was not the focus of the investigation in the present research, but an increasing development of antibiotic resistance of $S$. marcescens and $P$. mirabilis against ceftazidime was observed. Clinical studies have shown that the beta-lactam inhibitor combination of piperacillin-tazobactam is an effective medication for patients suffering from nosocomialacquired pneumonia [36]. Piperacillin-tazobactam and cefepime showed similar effectiveness against Gramnegative bacteria, but $S$. marcescens and $P$. mirabilis developed greater resistance to piperacillin-tazobactam in the present study. Due to this elevated resistance, piperacillintazobactam represents an essential support option in the treatment of nosocomial infections.

Resistance to tobramycin can be noted in numerous stages and is generally high due to the preservation of aminoglycoside-modifying enzymes [37]. Tobramycin showed increasing resistance rates in $S$. marcescens and $P$. mirabilis in the present study in hospitalized patients with pneumonia. Tobramycin was not as commonly tested in this study, but its efficacy was reduced in the antibiograms of the hospitalized patients with pneumonia.

Co-trimoxazole (a combination of trimethoprim and sulfamethoxazole) was effective in the study groups with pneumonia due to $S$. marcescens or $P$. mirabilis, but Gram-negative bacteria also showed significant resistance to co-trimoxazole in the present study. The range of effectiveness of the co-trimoxazole combination favors eradication of Gram-positive and Gram-negative 
microorganisms, although it is also effective against protozoa and some types of fungi [38].

Cefotaxime acts against Gram-positive and Gramnegative microbes, but elevated antibiotic resistance of $S$. marcescens and $P$. mirabilis to cefotaxime was evident in the present study population [39].

Tetracyclines are bacteriostatic toward Gram-positive and Gram-negative microbes [40]. Despite the description of good efficacy of tetracycline in the medical literature, it was poorly effective against $S$. marcescens and $P$. mirabilis pneumonia in the present investigation and increased development of resistance was apparent in these bacteria.

Piperacillin has the broadest range of activity of all penicillins toward Gram-positive and Gram-negative microorganisms, including Pseudomonas and Enterobacteriaceae [41]. Piperacillin was significantly more effective against Gram-negative isolates in patients with pneumonia than were the other representatives of penicillin, but $S$. marcescens and $P$. mirabilis showed resistance to it in the present investigation. Piperacillin was more effective against $S$. marcescens and P. mirabilis-associated pneumonia in the present study when combined with betalactamase inhibitors.

Cefuroxime has increased activity against Gramnegative rods when compared to first-generation cephalosporins. It also shows high stability against betalactamases [42]. Therefore, cefuroxime can be used for the initial therapy of pneumonia due to beta-lactamaseproducing strains. In the current period of rapidly growing bacterial resistance, the appropriate use of new antibacterial agents would be favored in the empirical treatment of pneumonia [43]. Due to the resistance to cefuroxime apparent in the antibiograms of isolates from tracheal secretions of inpatients with pneumonia in the present investigation, an empirical treatment would not be recommended for suspected pneumonia due to $S$. marcescens or P. mirabilis.

Ampicillin is effective against Gram-positive and some Gram-negative microorganisms; therefore, it is called a broad-range antimicrobial agent [44]. However, Gramnegative bacteria in hospitalized patients suffering from pneumonia showed the strongest resistance to ampicillin in the present investigation. The susceptibility testing indicated by the antibiograms of isolates recovered from inpatients with pneumonia in this clinical research indicated that $S$. marcescens and $P$. mirabilis were resistant to ampicillin, as expected. Ampicillin in combination with beta-lactam inhibitors showed better results, based on the susceptibility testing of tracheal secretions from inpatients with pneumonia triggered by S. marcescens or P. mirabilis in this study. Ampicillin-sulbactam has proven to be an important antimicrobial agent in the therapeutic arsenal for the effective treatment of pneumonia [45].
Antibiotic resistance in pathogens causing respiratory tract infections has increased dramatically in recent years. Resistance to penicillins due to beta-lactamase production has become a widespread problem around the world [46]. The careful selection of antibiotics with low potential for resistance, in addition to actively working against the further development of penicillin resistance, is the best current strategy.

\section{Study limitations}

This clinical research explains the state of antibiotic resistance in inpatients with pneumonia triggered by $S$. marcescens or P. mirabilis in a single teaching hospital, so the study results cannot be related to different geographical regions. Interpretation of the study data revealed that not all of the antimicrobial agents were examined in equal quantities in the susceptibility testing of inpatients with pneumonia triggered by $S$. marcescens or P. mirabilis. The authors were not able to clarify whether all the antimicrobial agents were analyzed for each isolate of $S$. marcescens and P. mirabilis.

\section{Conclusions}

All the study patients with pneumonia due to $S$. marcescens or $P$. mirabilis presented antibiotic resistance to a diversity of antimicrobial agents, but none showed resistance to cefepime. All common antimicrobial agents must be examined for effectiveness in the event of detection of Gram-negative bacteria on agar plates, for all patients who are identified with pneumonia. This should be done both for the immediate antimicrobial management of patients with pneumonia triggered by Gramnegative bacteria and for observing the temporal formation of antibiotic resistance in Gram-negative pathogens in subsequent periods.

\section{Abbreviations \\ CLSI: clinical and Laboratory Standards Institute; CRP: c-reactive protein; $\mathrm{Cl}$ : confidence interval; EUCAST: europe-wide standards for susceptibility testing; ICD: international Classification of Diseases; MALDI-TOF-MS: matrix assisted laser desorption ionization time-of-flight mass spectrometry; MIC: minimum inhibitory concentration; SD: standard deviation.}

\section{Competing interests}

The authors declare that they have no competing interests.

\section{Authors' contributions}

$J Y$ is responsible for the entire manuscript. The main author conceived and designed the experiments, performed the experiments, and analyzed the data. The main author contributed reagents, materials, and analysis tools. The main author wrote the entire manuscript. BG was responsible for microbiological testing and proofreading of the manuscript. KR was responsible for the development of the study design and final approval of the manuscript. All authors have read and approved of the final version of the manuscript.

\section{Author details}

${ }^{1}$ Department of Internal Medicine, Division of Pulmonary, Allergy and Sleep Medicine, HELIOS Clinic Wuppertal, Witten/Herdecke University, Witten, Germany. ${ }^{2}$ Witten/Herdecke University, Institute of Medical Laboratory 
Diagnostics, Center for Clinical and Translational Research, HELIOS Clinic Wuppertal, Witten, Germany.

\section{Received: 19 September 2015 Accepted: 17 February 2016 Published online: 23 March 2016}

\section{References}

1. Höffken G. Clinical requirements in the treatment of today's respiratory tract infections. Respiration. 1993:60 suppl 1:3-9.

2. Koulenti D, Rello J. Gram-negative bacterial pneumonia: aetiology and management. Curr Opin Pulm Med. 2006;12:198-204.

3. Restrepo MI, Anzueto A. The role of gram-negative bacteria in healthcareassociated pneumonia. Semin Respir Crit Care Med. 2009:30:61-6.

4. GlobalRPh. Gram Negative Bacteria, Gram-Negative Cocci \& Coccobacilli, Non-fermenting Gram-negative bacilli, Anaerobic Gram-Negative Bacilli. 2013. http://www.globalrph.com/bacterial-strains-gram-negative.htm. Accessed 2 March 2015.

5. Wong WW, Wang LS, Cheng DL, Lin SJ, Chin TD, Hinthorn DR, et al. Serratia marcescens bacteremia. J Formos Med Assoc. 1991;90:88-93.

6. Samonis G, Vouloumanou EK, Christofaki M, Dimopoulou D, Maraki S, Triantafyllou E, et al. Serratia infections in a general hospital: characteristics and outcomes. Eur J Clin Microbiol Infect Dis. 2011:30:653-60.

7. O'Hara CM, Brenner FW, Miller JM. Classification, identification, and clinical significance of Proteus, Providencia, and Morganella. Clin Microbiol Rev. 2000;13:534-46

8. Okimoto N, Hayashi T, Ishiga M, Nanba F, Kishimoto M, Yagi S, et al. Clinical features of Proteus mirabilis pneumonia. J Infect Chemother. 2010;16:364-6.

9. Torres A, Blasi F, Peetermans WE, Viegi G, Welte T. The aetiology and antibiotic management of community-acquired pneumonia in adults in Europe: a literature review. Eur J Clin Microbiol Infect Dis. 2014;33:1065-79.

10. Woodhead M. Community-acquired pneumonia in Europe: causative pathogens and resistance patterns. Eur Respir J Suppl. 2002;36:20s-7.

11. Zumla A, Memish ZA, Maeurer M, Bates M, Mwaba P, Al-Tawfig JA, et al. Emerging novel and antimicrobial-resistant respiratory tract infections: new drug development and therapeutic options. Lancet Infect Dis. 2014;14:1136-49

12. World Health Organization (WHO). International classification of diseases (ICD). http://www.who.int/classification/icd/en/. Accessed 2 March 2015.

13. Niederman MS, Mandell LA, Anzeuto A, Bass JB, Groughton WA, Campbell $\mathrm{GD}$, et al. American Thoracic Society. Guidelines for the management of adults with community-acquired pneumonia. Diagnosis, assessment of severity, antimicrobial therapy, and prevention. Am J Respir Crit Care Med. 2001;163:1730-54.

14. Watkins RR, Lemonovich TL. Diagnosis and management of communityacquired pneumonia in adults. Am Fam Physician. 2011;83:1299-306.

15. Clinical and Laboratory Standards Institute. Performance standards for antimicrobial susceptibility testing. CLSI M100-S22. Clinical and Laboratory Standards Institute, Wayne, Pad; 2012

16. European committee on antimicrobial susceptibility testing (EUCAST) breakpoints 2011-2014. http://www.eucast.org. Accessed 2 March 2015.

17. Bauer AW, Kirby WM, Sherris JC, Turck M. Antibiotic susceptibility testing by a standardized single disk method. Am J Clin Pathol. 1966;45:493-6.

18. Barlett JG. Diagnosis of bacterial infections of the lung. Clin Chest Med. 1987;8:119-34

19. VassarStats [website for statistical computation] and Concepts \& Applications of Inferential Statistics [companion textbook]. http://vassarstats. net/ and http://vassarstats.net/textbook/. Accessed 2 March 2015.

20. Tumah $\mathrm{H}$. Fourth-generation cephalosporins: in vitro activity against nosocomial gram-negative bacilli compared with beta-lactam antibiotics and ciprofloxacin. Chemotherapy. 2005;51:80-5.

21. Burgess DS, Frei CR. Comparison of beta-lactam regimens for the treatment of gram-negative pulmonary infections in the intensive care unit based on pharmacokinetics/pharmacodynamics. J Antimicrob Chemother. 2005:56:893-8.

22. Montgomery AB, Rhomberg PR, Abuan T, Walters KA, Flamm RK. Potentiation effects of amikacin and fosfomycin against selected amikacinnonsusceptible Gram-negative respiratory tract pathogens. Antimicrob Agents Chemother. 2014:58:3714-9.

23. Green DL. Selection of an empiric antibiotic regimen for hospital-acquired pneumonia using a unit and culture-type specific antibiogram. J Intensive Care Med. 2005;20:296-301.
24. Chapman TM, Perry CM. Cefepime: a review of its use in the management of hospitalized patients with pneumonia. Am J Respir Med. 2003:2:75-107.

25. Michalopoulos AS, Livaditis IG, Gougoutas V. The revival of fosfomycin. Int J Infect Dis. 2011:15:e732-9.

26. Karageorgopoulos DE, Wang R, Yu XH, Falagas ME. Fosfomycin: evaluation of the published evidence on the emergence of antimicrobial resistance in Gram-negative pathogens. J Antimicrob Chemother. 2012;67:255-68.

27. Falagas ME, Giannopoulou KP, Kokolakis GN, Rafailidis PI. Fosfomycin: use beyond urinary tract and gastrointestinal infections. Clin Infect Dis. 2008;46:1069-77.

28. Papp-Wallace KM, Endimiani A, Taracila MA, Bonomo RA. Carbapenems: past, present, and future. Antimicrob Agents Chemother. 2011;55:4943-60.

29. Baldwin CM, Lyseng-Williamson KA, Keam SJ. Meropenem: a review of its use in the treatment of serious bacterial infections. Drugs. 2008;68:803-38.

30. Croom KF, Goa KL. Levofloxacin: a review of its use in the treatment of bacterial infections in the United States. Drugs. 2003;63:2769-802.

31. West M, Boulanger BR, Fogarty C, Tennenberg A, Wiesinger B, Oross $M$, et al Levofloxacin compared with imipenem/cilastatin followed by ciprofloxacin in adult patients with nosocomial pneumonia: a multicenter, prospective, randomized, open-label study. Clin Ther. 2003;25:485-506.

32. Yamaguchi K, Ishii Y, Yamanaka K, Watanabe N, Uehara N, Kaku M, et al. [Nationwide susceptibility surveillance of ciprofloxacin and various parenteral antimicrobials against bacteria isolated from patients with severe infections - third ciproxan injection special survey (2005)]. Jpn J Antibiot. 2008;61:241-68 [Article in Japanese].

33. Okimoto N, Yamato K, Honda Y, Kurihara T, Osaki K, Asaoka N, et al. Clinical effect of intravenous ciprofloxacin on hospital-acquired pneumonia. J Infect Chemother. 2005:11:52-4.

34. Chen C, Chen Y, Wu P, Chen B. Update on new medicinal applications of gentamicin: evidence-based review. J Formos Med Assoc. 2014;113:72-82.

35. Choi SH, Koh Y. Ceftazidime for respiratory infections. Expert Opin Pharmacother. 2012;13:2097-109.

36. Gin A, Dilay L, Karlowsky JA, Walkty A, Rubinstein E, Zhanel GG. Piperacillintazobactam: a beta-lactam/beta-lactamase inhibitor combination. Expert Rev Anti Infect Ther. 2007:5:365-83.

37. Periti P. [Tobramycin-clinical pharmacology and chemotherapy] J Chemother. 1996:8 suppl 1:3-30 [Article in Italian].

38. Cockerill FR, Edson RS. Trimethoprim-sulfamethoxazole. Mayo Clin Proc. 1991;66:1260-9.

39. Plosker GL, Foster RH, Benfield P. Cefotaxime. A pharmacoeconomic review of its use in the treatment of infections. Pharmacoeconomics. 1998:13.91-106

40. Griffin MO, Fricovsky E, Ceballos G, Villareal F. Tetracyclines: a pleitropic family of compounds with promising therapeutic properties. Review of the literature. Am J Physiol Cell Physiol. 2010;299:C539-48.

41. Holmes B, Richards DM, Brogden RN, Heel RC. Piperacillin. A review of its antibacterial activity, pharmacokinetic properties and therapeutic use. Drugs. 1984:28:375-425.

42. Ergova R, K'oleian E, Kharalambieva I, Mitov I, Docheva LU. [A comparative study of antibacterial activity of ceftibuten, ceftazidime, cefuroxime and ampicillin against clinical isolates]. Vutr Boles. 2000;32:13-7 [Article in Bulgarian].

43. Scott LJ, Ormrod D, Goa KL. Cefuroxime axetil: an updated review of its use in the management of bacterial infections. Drugs. 2001;61:1455-500.

44. Kaushik D, Mohan M, Borade DM, Swami OC. Ampicillin: rise fall and resurgence. Clin Diagn Res. 2014;8:ME01-3.

45. Wright AJ. The penicillins. Mayo Clin Proc. 1999:74:290-307.

46. Dominguez MA, Pallares R. Antibiotic resistance in respiratory pathogens. Curr Opin Pulm Med. 1998:4:173-9. 